\title{
A case of orbital sebaceous gland carcinoma developing in an anophthalmic socket 65 years after enucleation
}

This article was published in the following Dove Press journal:

Clinical Ophthalmology

12 September 2013

Number of times this article has been viewed

\author{
Motoko Shibatal,* \\ Yoshihiko Usuil,* \\ Shunichiro Ueda' \\ Hajime Matsumura ${ }^{2}$ \\ Toshitaka Nagao 3 \\ Hiroshi Goto' \\ 'Department of Ophthalmology, \\ ${ }^{2}$ Department of Plastic and \\ Reconstructive Surgery, ${ }^{3}$ Department \\ of Anatomic Pathology, Tokyo Medical \\ University, Tokyo, Japan \\ *These authors contributed equally \\ to this work
}

\begin{abstract}
Although conjunctival squamous cell carcinoma is known to develop as a result of chronic irritation from wearing an ocular prosthesis, orbital sebaceous gland carcinoma arising in an anophthalmic pocket is extremely rare. We report a 68-year-old female who developed a sebaceous gland carcinoma 65 years after her right eye was enucleated (at the age of three years) due to congenital glaucoma. The patient had noticed increasing discharge and swelling of her right eyelid. Incisional biopsies of an underlying orbital mass revealed poorly differentiated sebaceous gland carcinoma. The sebaceous gland carcinoma in this case could have been caused by chronic irritation as a result of long-standing use of a poorly fitted ocular prosthesis. The current case of a malignant tumor occurring 65 years after enucleation emphasizes the importance of long-term clinical surveillance to monitor for tumor formation. Careful examination of the anophthalmic socket should be part of the physical examination.
\end{abstract}

Keywords: sebaceous gland carcinoma, anophthalmos, orbit

\section{Introduction}

Malignant tumor arising in an anophthalmic orbit, without a history of other malignant tumors, is extremely rare. A review of the literature regarding malignant tumors arising from an anophthalmic socket identified several cases of squamous carcinoma, ${ }^{1-4}$ and melanoma, ${ }^{5-8}$ but only one case of sebaceous gland carcinoma. ${ }^{9}$ This report describes a unique case of orbital sebaceous gland carcinoma that developed 65 years after enucleation due to congenital glaucoma.

\section{Case report}

A 68-year-old woman presented in the Department of Ophthalmology of Tokyo University with swelling and non-bloody discharge in her right eyelid, which had developed over several months. The right eye had been enucleated at the age of three years old, due to congenital glaucoma. She did not undergo orbital implant surgery at that time. Apart from the enucleation, the patient had an unremarkable medical history, and no family history of malignancy. She had worn the original ocular prosthesis for more than 60 years without maintenance. Since one year before presentation, the patient noticed increasing difficulty in wearing the prosthesis.

On examination, a firm mass was palpable beneath the right upper and lower eyelids. Cilia were present in both upper and lower right eyelids. Gadoliniumenhanced magnetic resonance imaging revealed a contrast enhanced mass measuring $38 \mathrm{~mm} \times 33 \mathrm{~mm} \times 36 \mathrm{~mm}$ in the right orbit (Figure 1). A clinical work-up for systemic 


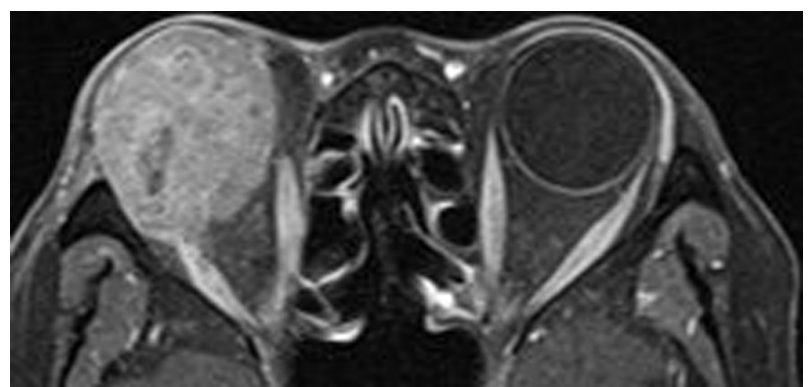

Figure I Axial gadolinium-enhanced TI-weighted magnetic resonance image shows a mass lesion in the anophthalmic orbit, which is totally occupied by the tumor.

disease, including complete blood cell count, chemistry panel, liver enzyme panel and imaging of the chest, was negative. There was no regional lymphadenopathy, and gallium scintigraphy revealed no systemic metastasis. A histopathologic examination of transcutaneous excisional biopsies of the mass revealed lobular aggregates of atypical basaloid cells, separated by fibrovascular stroma, and an inflammatory infiltration. The atypical cells had abundant clear multi-vacuolated cytoplasm, and oval nuclei with discernible nucleoli (Figure 2A). Tumor cells were immunoreactive for adipophilin and perilipin, which are useful markers for sebaceous gland carcinoma (Figure 2B). ${ }^{10}$ Esentreration of the right orbit was planned by performing multiple map biopsies, including the upper and lower eyelid skin, tarsus, orbicular muscle and skin, and deep tissues below the eyebrow. Within a month, the patient underwent orbital exenteration to excise the entire mass. The tumor had well defined margins and was enclosed by a capsule (Figure 3). No spread to other
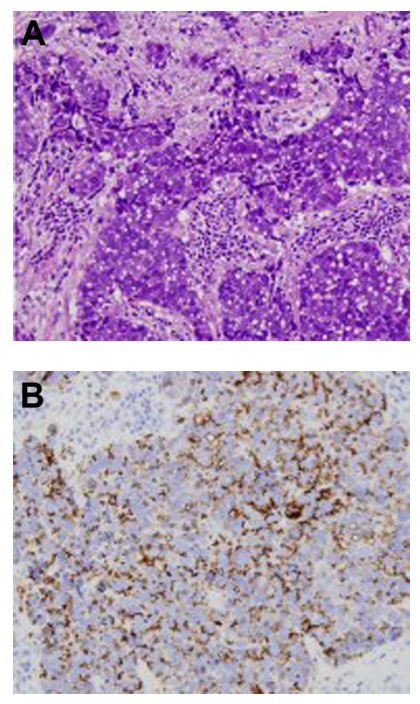

Figure 2 Hematoxylin-eosin stained section shows cells with abundant multivacuolated cytoplasm and large nuclei with prominent nucleoli; $\times 400$ (A). Adipophilin immunostaining highlights intracellular compartmentalized vacuoles; $\times 400$ (B).

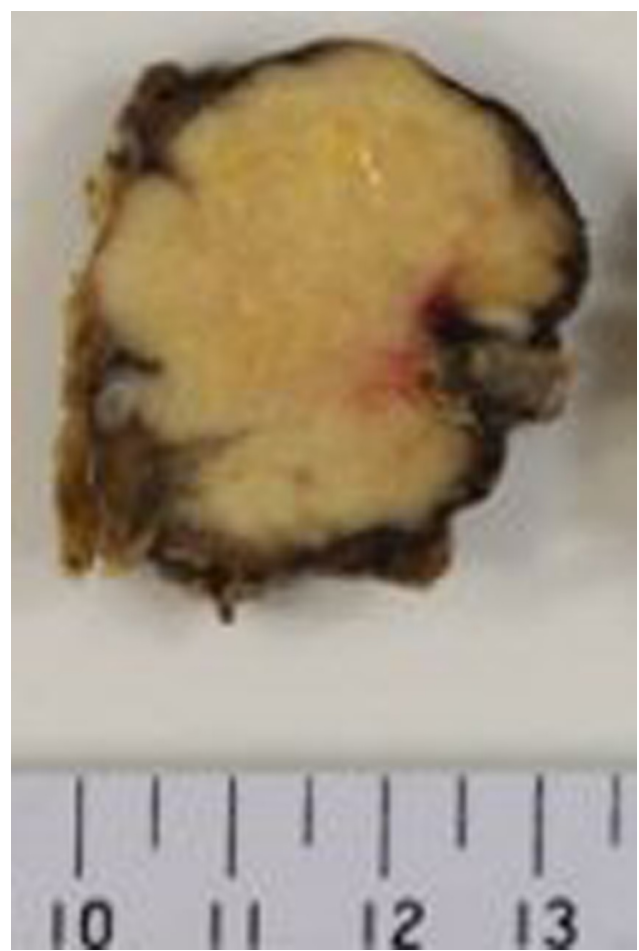

Figure 3 Gross appearance of the orbital tumor after exenteration. Note the tumor with well defined margin and enclosed by a fibrous capsule.

sites were observed. Histopathologic examination of the excised tumor demonstrated a poorly differentiated sebaceous gland carcinoma with negative margins. The eye socket was reconstructed using a free rectus abdominal muscle flap and mucosal graft. The patient recovered well, and was able to wear a prosthesis after surgery. There was no evidence of recurrence of metastasis ten months after orbital exenteration.

\section{Discussion}

Only one case of orbital sebaceous gland carcinoma that developed in an anophthalmic orbit after enucleation has been reported in English literature. ${ }^{9}$ In that case, enucleation was performed due to sympathetic opthalmia, and a sebaceous gland carcinoma developed in the anophthalmic orbit 27 years after enucleation. The carcinoma spread to lymph modes, and was speculated to arise from the sebaceous glands in the lacrimal caruncle. In the present case, a poorly differentiated sebaceous gland carcinoma developed in an anophthalmic orbit, 65 years after enucleation.

Sebaceous gland carcinomas generally arise in the ocular adnexa, which may be related to the high densities of Meibomian and Zeiss glands in the eyelids, and may also arise from sebaceous glands in the eyebrows and caruncle. ${ }^{11}$ We conducted multiple map biopsies considering the diverse sites from which the tumor could have been generated. Apart 
from the tumor, no neoplastic findings were found in any of the other biopsies. Thus, the origin of the sebaceous gland carcinoma in the present case remains unidentified.

In previous reports, chronic irritation from wearing a prosthesis for more than 40 years was suspected to be associated with the development of conjunctival squamous cell carcinoma and melanoma. ${ }^{1-4,12,13}$ In our patient's case, chronic irritation may also have played a role, as the patient had worn the original prosthesis for more than 60 years without routine maintenance.

When a patient wearing an ocular prosthesis presents with discharge, swelling, recent onset of poor fitting of the prosthesis, and a palpable orbital mass, the ophthalmologist should conduct a careful examination of the anophthalmic socket for possible malignant neoplasms. Insidious progression, such as tumor development within the anophthalmic socket, as in the present case, may masquerade as blepharitis, hindering early detection and resulting in delayed diagnosis. The prosthesis should also be examined for surface irregularities and damage, which may be a source of tumor development.

Malignant neoplasms may develop from sebaceous glands in the anophthalmic orbit over long periods after enucleation. Long-term follow-up is necessary to monitor the anophthalmic socket as well as the prosthesis.

\section{Acknowledgements}

This work was supported in part by the 'Strategic ResearchBased Support' Project for private universities; with matching funds from MEXT (Ministry of Education, Culture, Sports, and Science), Japan, and the Tokyo Medical University Cancer Research Foundation.

\section{Disclosure}

The authors report no conflicts of interest in this work.

\section{References}

1. Nguyen J, Ivan D, Esmaeli B. Conjunctival squamous cell carcinoma in the anophthalmic socket. Ophthal Plast Reconstr Surg. 2008;24(2): 98-101.

2. Endo T, Hata J, Togashi S, Yanagibayashi S, Nakayama Y. Conjunctival squamous cell carcinoma of the orbit 40 years after enucleation. Ophthal Plast Reconstr Surg. 2006;22(4):299-301.

3. Campanella PC, Goldberg SH, Erlichman K, Abendroth C. Squamous cell tumors and ocular prostheses. Ophthal Plast Reconstr Surg. 1998; 14(1):45-49.

4. Espana EM, Levine M, Schoenfield L, Singh AD. Ocular surface squamous neoplasia in an anophthalmic socket 60 years after enucleation. Surv Ophthalmol. 2011;56(6):539-543.

5. Levine RA, Putterman AM, Korey MS. Recurrent orbital malignant melanoma after the evisceration of an unsuspected choroidal melanoma. Am J Ophthalmol. 1980;89(4):571-574.

6. MacDonald R Jr, Edwards WC. Melanoma of the orbit: an interesting case following evisceration. Surv Ophthalmol. 1967;12(3): 253-257.

7. Murthy GG, Ingole AB, Desai S. Malignant melanoma in eviscerated eyeball. Clin Experiment Ophthalmol. 2004;32(1):103-105.

8. Kita Y, Yabe H, Shikishima K, Takahashi K. A case of malignant melanoma occurring 63 years after evisceration. Nihon Ganka Gakkai Zasshi. 2001;105(1):52-57.

9. Tanaka T, Sato H, Tada A, Moriya T, Wada Y, Nishida K. Case of orbital sebaceous carcinoma developing twenty-seven years after enucleation. Jpn J Opthalmol. 2008;52(4):344-345.

10. Izumi M, Mukai K, Nagai T, et al. Sebaceous gland carcinoma of the eyelids: thirty cases from Japan. Pathol Int. 2008;58(8):483-488.

11. Shields JA, Demirci H, Marr BP, Eagle RC, Shields CL. Sebaceous gland carcinoma of the ocular region: a review. Surv Ophthalmol. 2005; 50(2):103-122.

12. Whittaker KW, Trivedi D, Bridger J, Sandramouli S. Ocular surface squamous neoplasia: report of an unusual case and review of literature. Orbit. 2002;21(3):209-215.

13. Barrett RV, Meyer DR, Carlson JA. Conjunctival squamous cell carcinoma in situ in the anophthalmic socket. Ophthal Plast Reconstr Surg. 2010;26(1):52-53.
Clinical Ophthalmology

\section{Publish your work in this journal}

Clinical Ophthalmology is an international, peer-reviewed journal covering all subspecialties within ophthalmology. Key topics include: Optometry; Visual science; Pharmacology and drug therapy in eye diseases; Basic Sciences; Primary and Secondary eye care; Patient Safety and Quality of Care Improvements. This journal is indexed on

\section{Dovepress}

PubMed Central and CAS, and is the official journal of The Society of Clinical Ophthalmology (SCO). The manuscript management system is completely online and includes a very quick and fair peer-review system, which is all easy to use. Visit http://www.dovepress.com/ testimonials.php to read real quotes from published authors. 